\title{
Giant Lipomas of the Hand. Our Experience
}

\section{Lipomas gigantes de la mano. Nuestra experiencia}

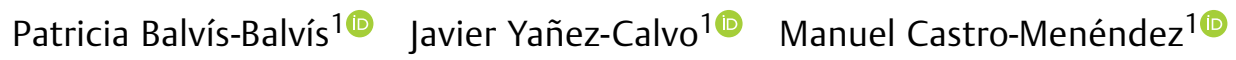 \\ María José Ferreirós-Conde ${ }^{1}$ \\ 1 Upper Limb Unit, Orthopedic Surgery and Traumatology Service, \\ Complejo Hospitalario Universitario de Vigo, Vigo, Pontevedra, \\ Spain \\ Rev Iberam Cir Mano 2020;48:72-78.

\begin{abstract}
Address for correspondence Manuel Castro Menéndez, MD, Servicio de Cirugía Ortopédica y Traumatología, Hospital Álvaro Cunqueiro, Complejo Hospitalario Universitario de Vigo (CHUVI), Avenida Clara Campoamor, 341, Vigo, Pontevedra, 36312, Spain
\end{abstract} \\ (e-mail: manuel.castro.menendez@sergas.es).
}

\begin{abstract}
Keywords

- lipoma

- liposarcoma

- hand

- tumor

\section{Resumen}

Objective Giant lipomas are benign tumors larger than $5 \mathrm{~cm}$ in size that are very uncommun in the hand, with the extant literature limited to case reports and small case series. The aim of the present study is to describe our experience with giant lipomas at the level of the hand, reviewing the most important aspects in relation to their diagnosis and treatment.

Material and Methods We present 6 patients treated in our service with giant lipomas of the hand between 2007 and 2015. Four cases only presented difficulty in grasping and mobilizing the hand due to the large size of the lipoma. Two cases were accompanied by a clinical feature of compression of the median nerve in relation to its location within the carpal tunnel.

Results All patients underwent surgery, and a complete excision of the lipoma was performed. The functional results have been satisfactory in all cases.

Conclusions Giant lipomas of the hand are infrequent tumors of slow growth, generally asymptomatic, although they can cause a compressive pathology due to the great size that they reach. Magnetic resonance imaging is an especially useful test to locate and accurately determine the size of the lesion in view of its surgical excision. After surgery, it is important to make a differential diagnosis with low-grade liposarcomas through an anatomopathological study, since both, macroscopically, have similar characteristics.

Objetivo Los lipomas gigantes son tumoraciones benignas de más de $5 \mathrm{~cm}$ de tamaño con localización infrecuente en la mano, limitándose la literatura a casos clínicos o series muy cortas. El objetivo de este trabajo es presentar nuestra experiencia con lipomas gigantes a nivel de la mano, revisando los aspectos más importantes en relación a su diagnóstico y tratamiento.

Material y Métodos Se presentan 6 casos de pacientes tratados en nuestro servicio con lipomas gigantes de la mano entre 2007 y 2015. Cuatro casos sólo presentaban dificultad para la prensión y movilización de la mano por el gran tamaño del lipoma. Los dos casos restantes se acompañaron de clínica compresiva del nervio mediano, en relación con su localización dentro del túnel carpiano.
\end{abstract}

received

January 8, 2020

accepted

July 7, 2020
DOI https://doi.org/

10.1055/s-0040-1716559.

ISSN 1698-8396.
Copyright $\odot 2020$ Thieme Revinter

Publicações Ltda, Rio de Janeiro, Brazil
License terms

(c) $9 \ominus \$$ 


\author{
Palabras clave \\ - lipoma \\ - liposarcoma \\ - mano \\ - tumor
}

\begin{abstract}
Resultados Todos los pacientes fueron intervenidos quirúrgicamente, realizándose una exéresis completa del lipoma. El resultado funcional y estético ha sido satisfactorio en todos los casos.

Conclusiones Los lipomas gigantes de la mano son tumoraciones infrecuentes de crecimiento lento, generalmente asintomáticas, aunque pueden producir patología compresiva debido al gran tamaño que llegan a alcanzar. La resonancia magnética es una prueba especialmente útil para localizar y determinar con exactitud el tamaño de la lesión en vista a su exéresis quirúrgica. Tras la cirugía, es importante hacer diagnóstico diferencial con los liposarcomas de bajo grado mediante un estudio anatomopatológico, ya que ambos, macroscópicamente, presentan características similares.
\end{abstract}

\section{Introduction}

Lipomas are benign tumors of mature adipocytes that can appear in any site with body fat. Most of them are located in the trunk, neck, thighs and shoulders; lipomas are rare in the hands, accounting for less than $5 \%$ of all benign tumors at this location. ${ }^{1,2}$ Giant hand lipomas are larger than $5 \mathrm{~cm},{ }^{1-5}$ and are even more rare. In fact, only individual clinical cases or small series of giant hand lipomas have been published in the literature. ${ }^{4}$ These tumors are usually asymptomatic and grow slowly. They are often diagnosed when large, because their mass can result in loss of function of the hand (mobility and grip deficits). Although the physical examination is crucial, imaging tests, such as magnetic resonance imaging (MRI), are useful for diagnostic guidance and preoperative planning, because they enable physicians to make an accurate determination of the size and location of the lesion for surgical excision. The MRI can also assist in the differential diagnosis with other conditions, including low-grade liposarcomas; however, an anatomopathological study of the resected specimen must be performed for diagnostic confirmation because these two conditions have similar macroscopic features. The present study aims to describe our experience with giant lipomas of the hand, reviewing the most important aspects regarding their diagnosis and treatment.

\section{Material and Methods}

Our series includes all patients with giant lipomas of the hand treated in our unit from 2007 to 2015. All subjects underwent surgery for tumor excision.

The series consists of 6 patients ( 3 male and 3 female) with a mean age of 65 years (range: 48 to 85 years) and a slowly growing tumor in the palm of the hand, not painful and with no known traumatic history. The right hand was affected in five patients, and the tumor was located on the left hand in a single patient. The mean size of the tumors was $7 \times 6 \mathrm{~cm}$ (range: $6 \times 3 \mathrm{~cm}$ to $11 \times 13 \mathrm{~cm}$ ), and the estimated mean time from tumor onset to the first medical visit was 5 years (range: 4 to 10 years).

Anatomically, all patients presented tumors in the palmar area of the hand. In two cases, only the area of the thenar eminence was affected, while the largest tumor covered the entire palmar surface, extending from the ulnar to the radial regions (-Figure $\mathbf{1}$ ).

Although all patients stated that their chief complaint was a large, non-painful tumor that limited grasping or hand movements, two patients also reported paresthesia in the medium territory, with a "sensation" of loss of strength. These subjects presented the two largest tumors, with significant extension to the carpal tunnel (-Figure 2). None of the patients referred pain (visual analog scale [VAS] for pain $=0$ ).

In addition to tumor size and characteristics, the mobility, strength, and sensitivity of the affected hand were clinically assessed.

The initial examination revealed that all patients presented normal mobility in the interphalangeal joints. However, the space occupied by the tumor limited the flexion range in the metacarpophalangeal joints of the long fingers in the three subjects with the largest palmar tumors (mean flexion: $75^{\circ}$; range: $70^{\circ}$ to $80^{\circ}$ ). The patient with the largest tumor $(11 \times 13 \mathrm{~cm})$ and severe involvement of the entire palm had difficulty performing pinch movements (- Figure $\mathbf{1 a}$ ).

An adequate measurement of strength using a Jamar (JLW Instruments, Chicago, IL, US) dynamometer was not performed because the presence of a significant palmar mass hinders this test. Strength normality was determined according to the Medical Research Council (MRC) modified measurement scale for hand muscles (MRC Scale), and all patients presented a 5/5 strength ("grade 5" - active range of motion and normal muscular resistance).

The patients who reported selected paresthesias were positive at the Durkan and Phalen tests, but negative at the Tinel test. Hypoesthesia areas or significant muscular atrophies were not observed. Since there were no other findings upon the neurological examination, additional electromyographic studies were considered unnecessary.

Hypercholesterolemia and body mass index (BMI) were assessed to analyze a potential relationship of these data with the presence of giant lipomas.

All subjects underwent a contrast-enhanced MRI (with a single dose of gadoteridol) as the additional imaging modality of choice to study a soft-tissue mass. In all cases, the MRI revealed well-defined, encapsulated tumors larger than $5 \mathrm{~cm}$, with a fat-like signal consistent with lipomas ( - Figure 3 ). In all patients, the MRI images showed the benignity criteria 

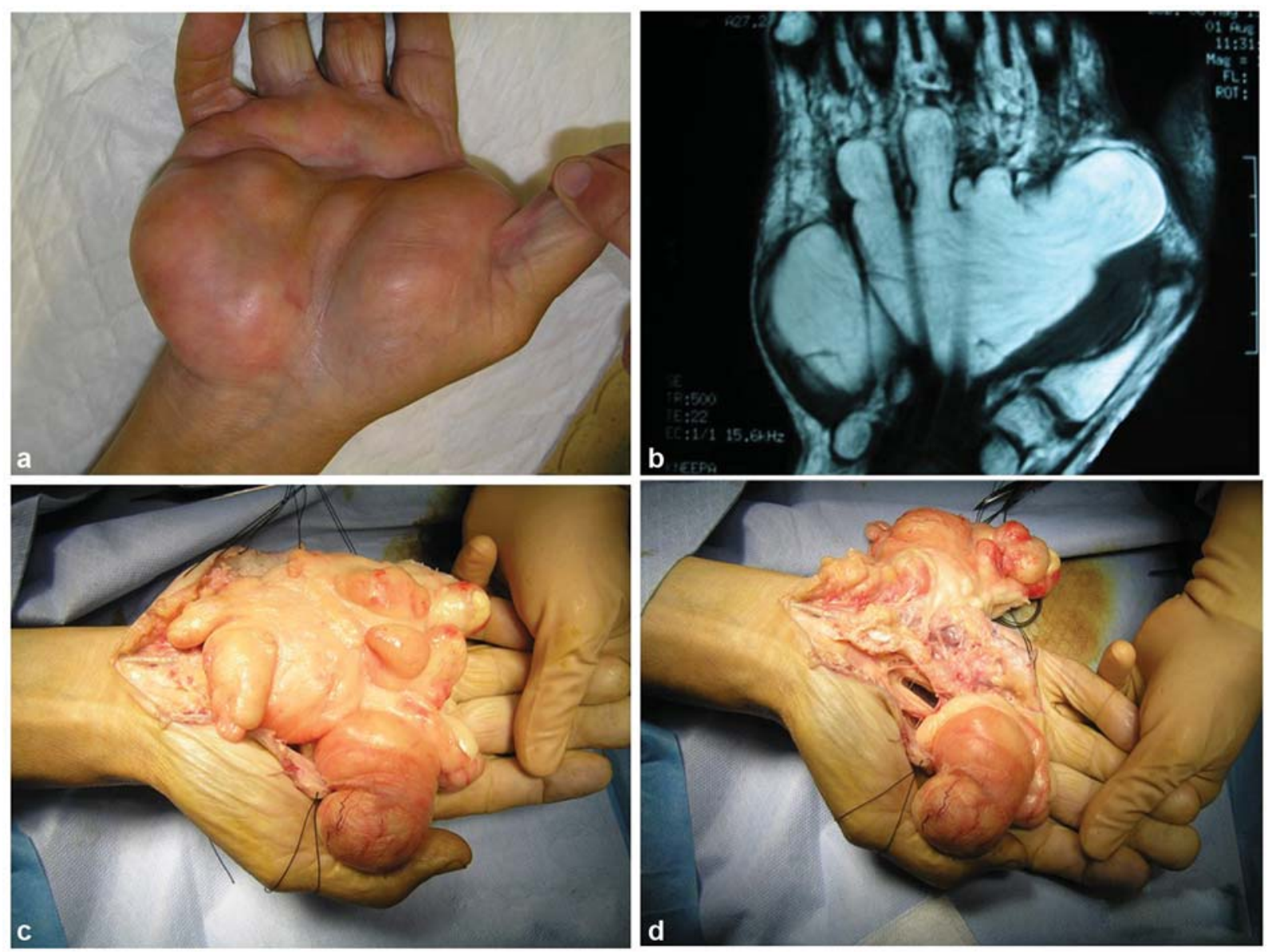

Fig. 1 Palmar tumor measuring $11 \times 13 \mathrm{~cm}$ in the right hand. (a) Clinical image of a palmar tumor with 2 years of evolution not associated with clinical compression in a 72-year-old man who complained of loss of manual function. (b) Magnetic resonance imaging scan of the patient shown in - Figure 1a; the lesion extends from the thenar eminence to the hypothenar eminence. (c and d) Intraoperative images of the same patient. A well-defined, encapsulated, multilobed tumor occupying the entire palm of the hand, from the thenar eminence to the hypothenar eminence, was exhaustively dissected.

reported by Ohguri, ${ }^{6}$ with no signs suggestive of malignancy, such as edge irregularity or signal alterations within the mass.

The surgical planning was based on MRI images, and the approach was designed for complete access to the mass while sparing tendons and neurovascular structures.

A preoperative biopsy was not performed because of the high diagnostic reliability provided by the $\mathrm{MRI}^{6,7}$ and the lack of consistency in the literature regarding the need to carry it out.

The surgeries were performed in the operating room, under regional anesthesia, with the patient in the supine position and using an ischemia cuff, but no Esmarch bandage. In the four subjects with palmar-central tumors, a transverse incision was made at the level of the distal palmar fold and distally or proximally expanded with Brunner-type incisions as needed. This is an easily expandable approach; we are used to it (Dupuytren surgery, tendon surgery etc.), and it enables a very good approach to these cases. In two subjects with palmar tumors, the mass extended to the dorsal area of the hand up to the region between the metacarpal bones; however, no additional dorsal approach was required, since this palmar approach was sufficient for complete tumor resection. Lipomas at the eminence were approached longitudinally: in one case, radial to the thenar eminence, and, in the other case, ulnar to it, depending on the exact location of the tumor. A drain was placed for 24 hours in all patients prior to skin closure. All specimens were sent to the Pathological Anatomy Service for analysis.

The mean postoperative follow-up period was of 8 years (range: 4 to 12 years).

The present research was carried out in compliance with the Helsinki Declaration, the study protocol, and the Good Clinical Practice (GCP) guidelines as described by the International Council for Harmonization of Technical Requirements for Pharmaceuticals for Human Use (ICH). All subjects provided their informed consent for the study according to the template for clinical cases from the Ethical Committee of Galicia, Spain.

\section{Results}

All patients presented a palmar tumor with subfascial location. In two subjects, only the area of the thenar eminence was affected, and in three patients a mass occupied a space in the central palm and at the level of the carpal tunnel, from the transverse carpal ligament to the metacarpal bones, extending throughout tendons and neurovascular structures of the central fingers. The largest lipoma occupied the entire 

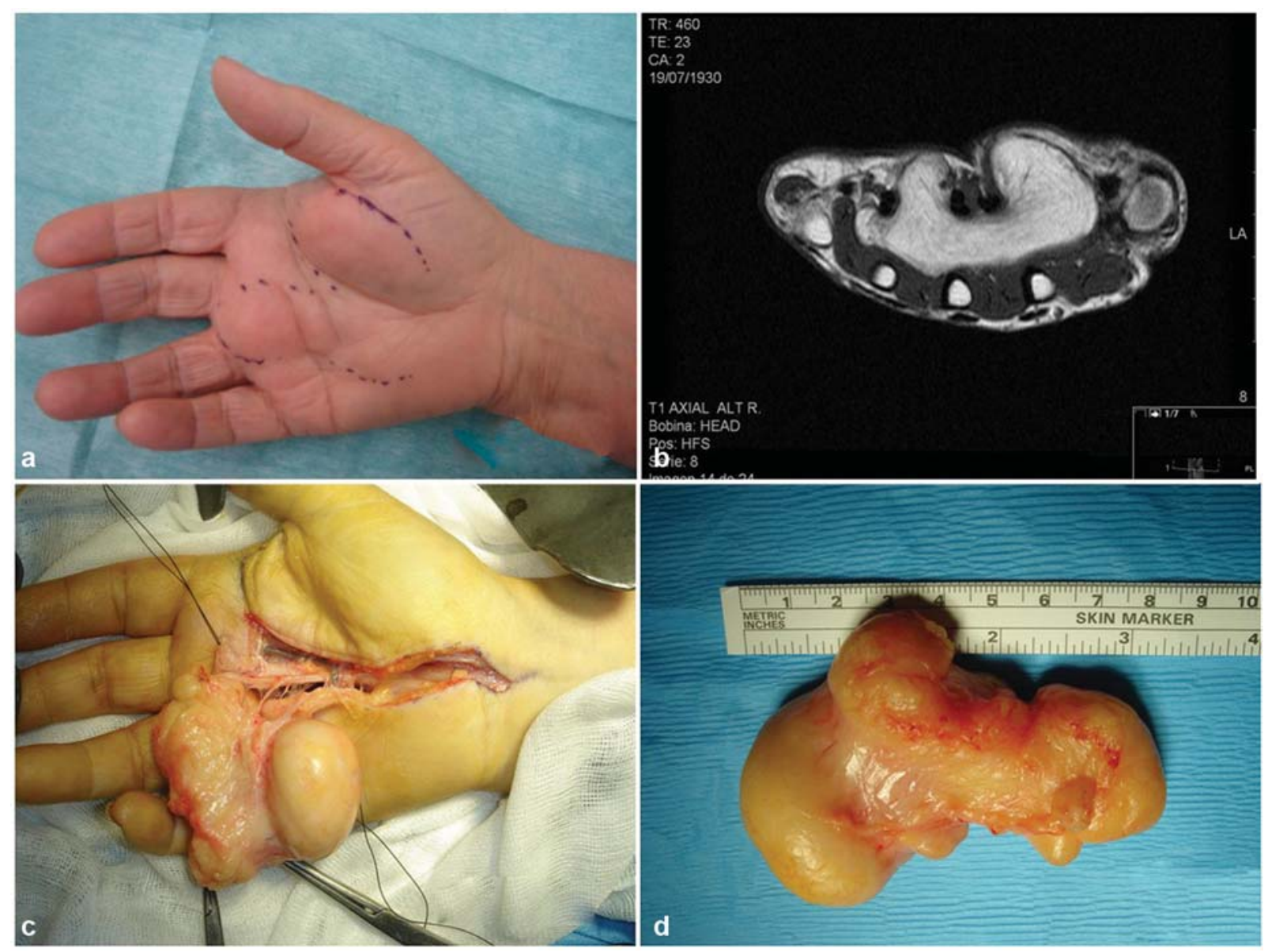

Fig. 2 Palmar tumor in the right hand of a 76-year-old woman. (a) Clinical image of a palmar tumor in a patient with paresthesia and slight loss of strength in the area of the median nerve. (b) Coronal magnetic resonance imaging scan of the patient shown in - Figure $2 \mathbf{a}$ revealing the interdigitation of the lipoma between the third and fourth compartments. (c) Lipoma dissection from the same patient; the tumor occupied the thenar eminence and extended through the third and fourth fingers. (d) Palmar tumor with $8 \times 3 \mathrm{~cm}$ in size.

palmar area, from the thenar to the hypothenar eminences (-Figure 1). The two lipomas at the thenar eminence were rounded (-Figure 3 ), while those at the palm were multilobed, with profuse interdigitation to hand structures (-Figures 1 and $\mathbf{2}$ ).

The mean size of the tumors after the resection was of $7 \times 6 \mathrm{~cm}$ (range: $6 \times 3 \mathrm{~cm}$ to $11 \times 13 \mathrm{~cm}$ ).

None of the patients had hypercholesterolemia, and only 1 subject had a BMI higher than 30 .

Dissection of the lipoma was simple in three subjects (two with thenar lesions and one presenting a palmar mass). In the three remaining patients, however, the tumors had significant lobulations and interdigitations in tendons and/or neurovascular structures of the hand, requiring more complex surgeries, in which nerve branches and vessels had to be identified and separated for complete lesion resection, while the vascularization, mobility or sensitivity were spared. Two cases required a fragmented excision of the lipoma (-Figures 1c and 1d) because the tumor was large and produced an "hourglass" effect around the median nerve and flexor tendons. This "hourglass" effect made excision in one piece without damaging the aforementioned structures impossible, so the tumor was divided into two parts to facilitate its extraction; one half was extracted from the part ulnar to the nerve, and the other, from the part radial to the nerve.

The anatomopathological analysis revealed that the lesions had a compact, yellowish parenchyma, with a fatty appearance and a thin capsule that completely encompassed the entire specimen. All tumors were benign.

All patients fully recovered hand function after the excision of the lipoma, achieving full range of motion in all joints and performing pinch movements.

None of the patients had nerve complications, and all subjects presented normal postoperative sensitivity and strength. The postoperative strength remained as "grade 5" according to the MRC scale (as in the preoperative visit). Paresthesias in the median nerve territory secondary to compression of the carpal tunnel disappeared completely after surgery.

The VAS score for pain remained 0 after the intervention.

As sole complication, two patients had a moderate postsurgical hematoma despite the placement of drains in the cavity after the resection. One of these subjects was undergoing an antiplatelet therapy, which may have contributed to hematoma formation. The manual expression of the collection after removing a suture from the wound resulted in its resolution and healing, with no complications. 

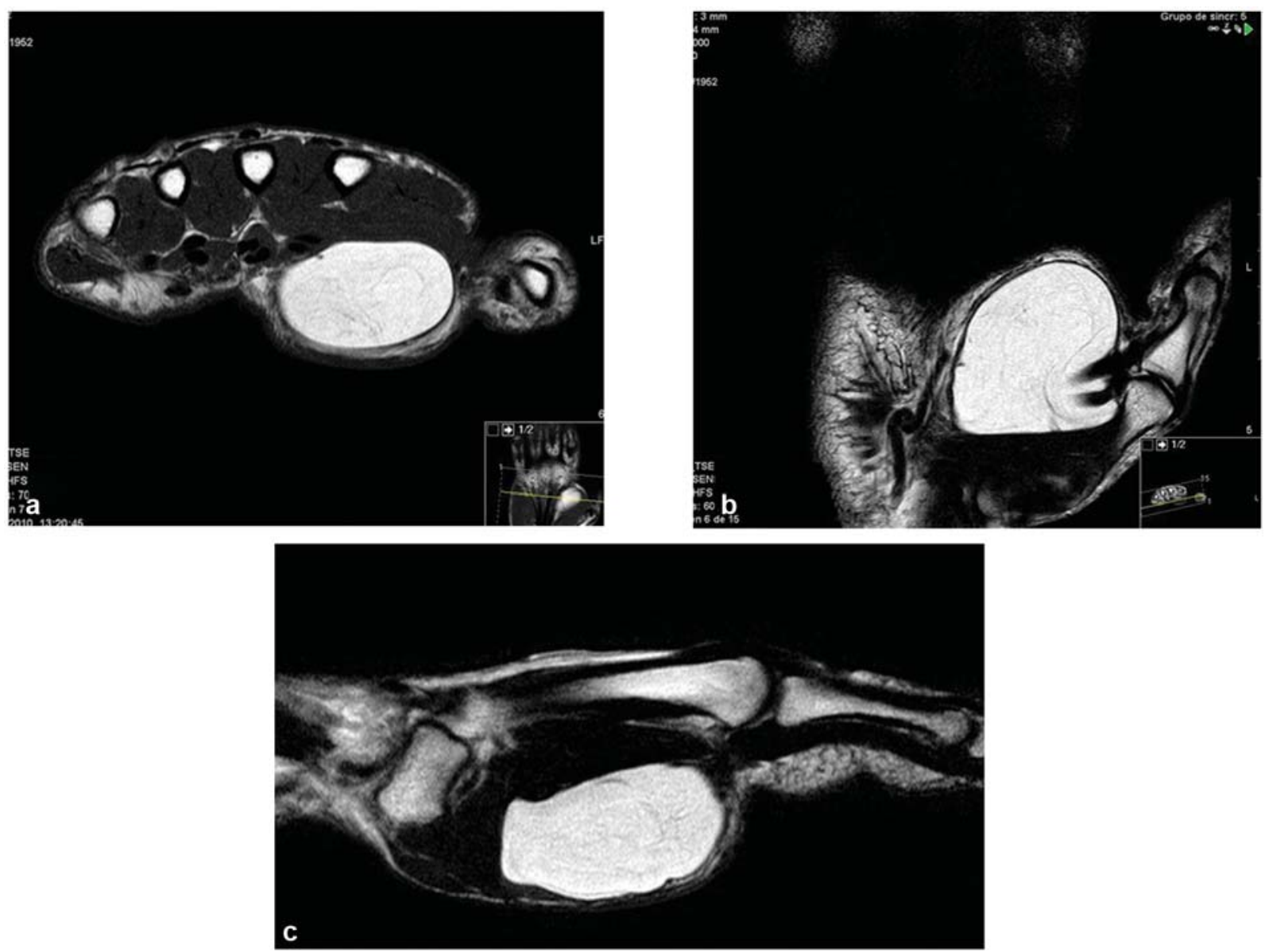

Fig. 3 Magnetic resonance imaging is the test of choice to study a lipoma. (a, b, and c) These images show a highly intense, well-defined, encapsulated, homogeneous mass at the level of the thenar eminence, a hallmark of benign lipomas.

None of the patients presented signs of infection.

There were no recurrences after a mean follow-up period of 8 years (range: 4 to 12 years).

\section{Discussion}

Lipomas are benign tumors of mesenchymal origin formed by mature adipocytes, and they have a low risk of malignant degeneration. ${ }^{2}$ Their etiology remains unclear, although trauma, inflammatory conditions, and genetic abnormalities may play a role. ${ }^{8}$ Specifically, obesity and hypercholesterolemia were related to the onset of lipomas. ${ }^{9}$ In our series, only one patient had hypercholesterolemia, and another one had a BMI higher than 30; however, the small sample size does not allow us to establish or rule out this association. Lipomas are usually diagnosed between the fifth and sixth decades of life, ${ }^{3,10}$ which is consistent with the mean age of our patients: 65 years (range: 48 to 85 years). Lipomas are usually slow-growing tumors, so they remain asymptomatic for a long time. ${ }^{5}$ Patients seek medical attention when the tumor becomes large and affects hand function, ${ }^{8-11}$ as occurred in all of our subjects (-Figure $\mathbf{1}$ ), or if they present compression-related clinical signs, especially at the level of the nerves ${ }^{1,3,5,11,12}$ (paresthesia, loss of strength etc.) in more advanced stages, as observed in two of our cases. Signs of nerve compression are related both to the size and location of the lesion. As such, giant lipomas of the hand can cause carpal tunnel syndrome due to the involvement of the median nerve $e^{3,5,13,14}$ (as in two of our patients, shown in - Figure 2), compression of the ulnar nerve at the level of the Guyon canal, or involvement of interdigital nerves. Even though compression-related nervous paralysis is reported in the literature, we did not observe this complication in our series. No compressive vascular symptoms were described both in the reviewed literature and in our cases. ${ }^{1,3,12}$ Although some authors state that ultrasonography has a valuable role in the initial evaluation of hand tumors, ${ }^{2}$ MRI is the imaging modality of choice for diagnostic guidance and preoperative planning. ${ }^{1,3,4,6,10,15}$ Capelastegui et $\mathrm{al}^{7}$ declare that the MRI provides a correct diagnosis in up to $94 \%$ of the cases due to its high sensitivity. The MRI indicates the lipomatous origin of the lesion, its local extension, and the relationships with neurovascular structures in the hand. In all of our cases, T1-weighted images revealed a high-intensity, homogeneous, well-delimited and encapsulated mass, the hallmark of benign lipomas (- Figure 3 ). Today, most authors ${ }^{11,15}$ consider that a preoperative biopsy of lipomas is only required if there are diagnostic doubts in MRI scans or a low-grade liposarcoma is suspected. There was no need for a preoperative biopsy in any of our cases, 
since the MRI findings always indicated the benign nature of the lesion. The risk of malignant transformation of a lipoma is very low, and liposarcomas of the hand are even rarer. ${ }^{16}$ If, on an exceptional basis, the anatomopathological analysis reported a low-grade sarcoma (the main differential diagnosis), having performed lesion excision instead of an incisional biopsy prior to resection would not have significantly changed the situation, since, in general, a wide-margin resection is not feasible in the hand. The treatment would simply consist of adding adjuvant radiation therapy to the tumor excision.

Lipomas can be located below or above the palmar fascia, and it is very rare to find them intra- or intermuscularly. Intramuscular lipomas can infiltrate muscle fibers and show an irregular margin compared to the well-defined margins of lipomas in other sites. ${ }^{8}$ No lipoma from our series had an intramuscular location. The goal of the treatment is complete surgical excision (-Figures 1 and 2). The dissection and identification of neurovascular elements during surgery are of utmost importance. ${ }^{1,3,10,17}$ Despite the fact that these tumors are usually well-located and easily dissected, their large size and occasional interdigitation with low-resistance areas complicate their resection. ${ }^{11}$ In two of our cases, large lipomas had an hourglass effect around the median nerve and flexor tendons, forcing the division of the tumor into two fragments for excision. Liposarcomas must be included in the differential diagnosis due to their large size. ${ }^{18-20}$ Any softtissue mass larger than $5 \mathrm{~cm}$ must be considered potentially malignant, so a correct pathology study of the specimen is crucial. $^{18,21}$ The identification of a possible malignant pathology is important because a more radical treatment may be required.,19,20 Liposarcoma is one of the most frequent soft-tissue sarcomas in adults, and it arises from subcutaneous fat or a pre-existing lipoma. ${ }^{20}$ The largest subgroup is well-differentiated liposarcoma, accounting for $40 \%$ to $45 \%$ of the cases. ${ }^{20,22}$ The term well-differentiated liposarcoma has been used to describe low-grade lipomatous neoplasms with a propensity for local recurrence. ${ }^{22}$ As already mentioned, it is exceptional to find this tumor in the hands. ${ }^{16}$ Its appearance is highly variable, ranging from a soft, smooth, lipoma-like neoplasm (common in low-grade liposarcomas) to a heterogeneous, irregular mass characteristic of a malignant tumor. According to Ohguri et al, ${ }^{6}$ the careful evaluation of the margins and internal features of the lesions through an MRI scan can aid in the distinction of benign lipomas from well-differentiated liposarcomas. The low risk of malignant transformation described in the literature $^{22}$ was observed in our series, in which $100 \%$ of giant lipomas were benign tumors. The literature does not describe many complications in this type of tumor and its excision. ${ }^{15}$ The most frequent complications are postoperative infection at the surgical wound, injuries to the neurovascular structures, and complex regional pain syndrome, none of them observed in our patients. As an anecdote, two of our patients presented postsurgical hematomas that resolved without incidents after a simple evacuation. Multiple papers describe local recurrences as rare, ${ }^{1,3,4,15}$ and they are usually caused by incomplete tumor excision. There were no recurrences in our series after an average follow-up of 8 years (range: 4 to 12 years).

\section{Conclusion}

Patients with giant lipomas of the hand usually seek medical attention because the tumor, although asymptomatic, is large enough to cause functional loss at the affected hand. The MRI is the modality of choice for the study of the tumor and the preoperative planning. Surgical excision is the treatment of choice in all cases, and the prognosis is good. Even though malignant transformation is infrequent, an adequate preoperative diagnosis and a pathological study are essential due to the large size of the tumor.

Conflict of Interests

The authors have no conflict of interests to declare.

\section{References}

1 Fnini S, Hassoune J, Garche A, Rahmi M, Largab A. Lipome géant de la main : présentation d'un cas clinique et revue de la littérature. Chir Main 2010;29(01):44-47

2 Chatterton BD, Moores TS, Datta P, Smith KD. An exceptionally large giant lipoma of the hand. BMJ Case Rep 2013;2013: bcr2013200206. Doi: 10.1136/bcr-2013-200206

3 Fazilleau F, Williams T, Richou J, Sauleau V, Le Nen D. Median nerve compression in carpal tunnel caused by a giant lipoma. Case Rep Orthop 2014;2014:654934

4 Cribb GL, Cool WP, Ford DJ, Mangham DC. Giant lipomatous tumours of the hand and forearm. J Hand Surg [Br] 2005;30 (05):509-512

5 De Smet L, Bande S, Fabry G. Giant lipoma of the deep palmar space, mimicking persistent carpal tunnel syndrome. Acta Orthop Belg 1994;60(03):334-335

6 Ohguri T, Aoki T, Hisaoka M, et al. . Differential diagnosis of benign peripheral lipoma from well-differentiated liposarcoma on MR imaging: is comparison of margins and internal characteristics useful? AJR Am J Roentgenol 2003;180(06):1689-1694

7 Capelastegui A, Astigarraga E, Fernandez-Canton G, Saralegui I, Larena JA, Merino A. Masses and pseudomasses of the hand and wrist: MR findings in 134 cases. Skeletal Radiol 1999;28(09): 498-507

8 Fraga J, García-Elías M, Lluch A. Lipomas Gigantes da Eminência Tenar. Rev Iberoam Cir Mano 2013;41(01):37-39

9 Santos-Maraver MT, Collado-Torres F, De la Torre-Solís F, Roson Mendez-Trelles JJ. Lipomas de la mano: cuatro nuevos casos. Revisión bibliográfica. Rev Orthop Traum. 1994;38(04): 297-301

10 Ramirez-Montaño L, Lopez RP, Ortiz NS. Giant lipoma of the third finger of the hand. Springerplus 2013;2(01):164

11 Higgs PE, Young VL, Schuster R, Weeks PM. Giant lipomas of the hand and forearm. South Med J 1993;86(08):887-890

12 Leffert RD. Lipomas of the upper extremity. J Bone Joint Surg Am 1972;54(06):1262-1266

13 Babins DM, Lubahn JD. Palmar lipomas associated with compression of the median nerve. J Bone Joint Surg Am 1994;76(09): 1360-1362

14 Jalan D, Garg B, Marimuthu K, Kotwal P. Giant lipoma: an unusual cause of carpal tunnel syndrome. Pan Afr Med J 2011;9:29

15 Grivas TB, Psarakis SA, Kaspiris A, et al. . Giant lipoma of the thenar-case study and contemporary approach to its aetiopathogenicity. Hand (NewYork) 2009;4:173-176

16 Irisarri C. Tumores de partes blandas en la mano. Rev Iberoam Cir Mano 1995;49(22):23-33 
78 Giant Lipomas of the Hand Balvís-Balvís et al.

17 Mota FP, Fahandezh-Saddi H, Hualda AL. Lipoma gigante bilobular en la mano: caso clínico y revisión de la literatura. Rev. Iberam. Cir. Mano 2011;39(01):70-74

18 Nadar MM, Bartoli CR, Kasdan ML. Lipomas of the hand: a review and 13 patient case series. Eplasty 2010;10:e66

19 Allen B, Rader C, Babigian A. Giant lipomas of the upper extremity. Can J Plast Surg 2007;15(03):141-144

20 Johnson CJ, Pynsent PB, Grimer RJ. Clinical features of soft tissue sarcomas. Ann R Coll Surg Engl 2001;83(03):203-205
21 Kooby DA, Antonescu CR, Brennan MF, Singer S. Atypical lipomatous tumor/well-differentiated liposarcoma of the extremity and trunk wall: importance of histological subtype with treatment recommendations. Ann Surg Oncol 2004;11(01):78-84

22 Laurino L, Furlanetto A, Orvieto E, Dei Tos AP. Well-differentiated liposarcoma (atypical lipomatous tumors). Semin Diagn Pathol $2001 ; 18(04): 258-262$ 